\title{
Heat Transfer Performance of a Gasketed Plate Heat Exchanger Subjected to Mechanical Vibration
}

\author{
أداء إنتقال الحرارة لمبادل حراري من النوع اللوحي مجز بمانع تسريب يهتز إهتزازا ميكانيكيا

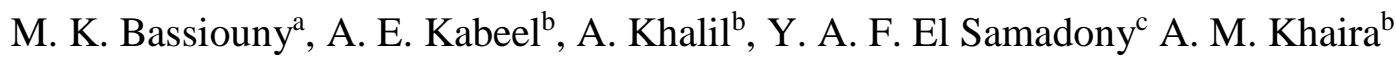 \\ ${ }^{a}$ Mechanical Power Eng. Dept. Faculty of Engineering, Menoufia University, Egypt. \\ ${ }^{b}$ Mechanical Power Eng. Dept. Faculty of Engineering, Tanta University, Egypt. \\ ${ }^{\mathrm{C}}$ Mechanical Eng. Dept. Faculty of Engineering, Beirut Arab University, Lebanon.
}

\begin{abstract}
الملخص
يتضمن البحث دراسة تأثير الاهتزاز ات الميكانيكية على خصائص انتقال الحرارة من حيث معامل انتقال الحرارة، معامل انتقال الحرارة الكلى وفعالية

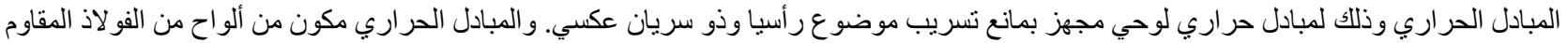

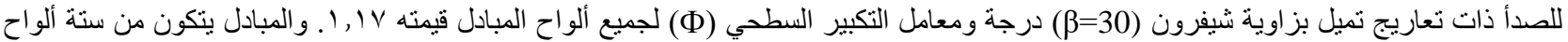

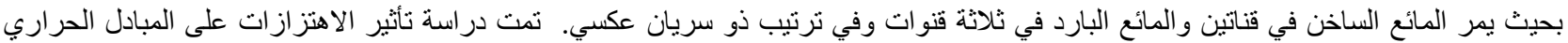

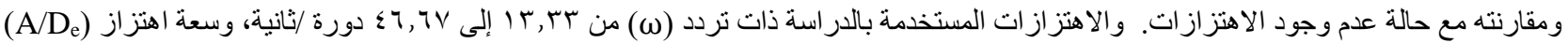

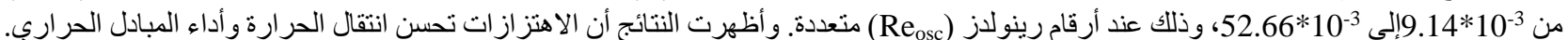

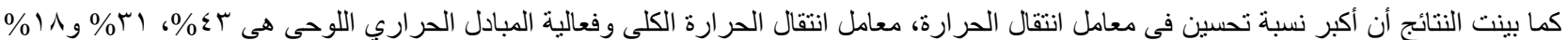

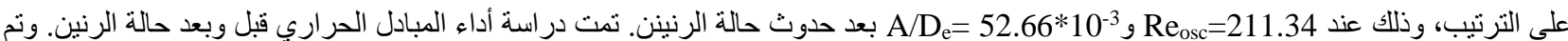

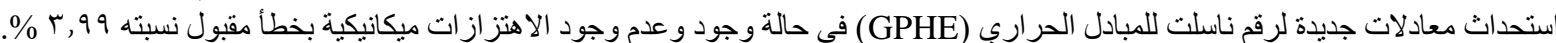

\begin{abstract}
Heat transfer characteristics in terms of heat transfer coefficient, overall heat transfer coefficient and heat exchanger effectiveness of a vertical counter flow Gasket plate heat exchanger (GPHE) are experimentally investigated. The tested PHE is made of stainless-steel plates with $30^{\circ}$ chevron angle $\left(\beta=30^{\circ}\right)$. The surface enlargement factor, $\Phi$ for all plates was 1.17. Six plates were installed; providing two hot channels and three cold channels in counter flow arrangement. The vibration effect on tested GPHE has been performed and compared with non-vibration model. Vibration frequencies $(\omega)$ are in the range of 13.33 to $46.67 \mathrm{cps}$ and vibrational dimensionless amplitude (A/ $\mathrm{D}_{\mathrm{e}}$ ) varied from $9.14 * 10^{-3}$ to $52.66^{*} 10^{-3}$ at various oscillating Reynolds numbers were employed. It is found that the heat transfer performance of the GPHE is enhanced when vibration is applied. The maximum enhancement percentage of the GPHE heat transfer coefficient, overall heat transfer coefficient and effectiveness due to vibration are $43 \%, 31 \%$ and $18 \%$, respectively. These maximums are occurred at oscillation Reynolds number of 211.34 and $\mathrm{A} / \mathrm{D}_{\mathrm{e}}=52.66^{*} 10^{-3}$ which after the resonance condition. The GPHE performance after and before resonance condition are obtained. Finally, correlations for GPHE Nusselt number, when vibration is and is not applied, are obtained with an acceptable error of $3.99 \%$.
\end{abstract}

Keywords: Mechanical vibration, gasket plate heat exchanger, Heat transfer enhancement.

\section{Introduction}

Heat exchangers are used in different processes like condensation, boiling, and conversion, utilization and recovery of thermal energy. Also, they are used in huge amount of applications, which include thermal power stations, sensible heating and cooling in thermal processing of chemical, pharmaceutical and agricultural products etc. [1]. A recent report of the IEA (International Energy Agency) [2] said

that heat represents $47 \%$ of the world's final energy consumption compared with $17 \%$ for

electricity, 27\% for transport and 9\% for "non-energy use. Knowing that $81 \%$ of the production of electricity comes essentially from heat and, almost $100 \%$ for transport, the efficiency of thermal processes is a key parameter in the energy economy. Increase in heat transfer enhancement can lead to more economical design of heat exchanger, which can help to make energy, material and cost savings related to a heat exchange process. GPHE have won increasing interest during the last two decades. This is primarily because the methods of manufacturing the plate corrugation patterns of these heat exchangers are continuously in development. Initially, the gasket plateand-frame type heat exchanger offers very good heat transfer performance in single phase flow as well as in evaporation and condensation. Other advantages of plate heat exchangers are; the small hydraulic diameters, the extremely compact design and the efficient use of the 
construction material [3, 4]. Finally, GPHE cleaning and maintenance is easy, and led to increase its efficiency and eliminate its fouling problem, which included in more than $90 \%$ of the others heat exchangers [5].

Generally, heat exchanger enhancement techniques can be classified broadly as passive and active techniques. Passive techniques do not require direct input of external power [6]. This method generally uses surface or geometrical modifications to the flow channel, or incorporates an inserts, material, or additional device. In the case of active techniques, the addition of external power essentially facilitates, the desired flow modification and the concomitant improvement in the rate of heat transfer's surface vibration is one of the active techniques, which has been considered by researchers for heat transfer enhancement. Surface vibrations increase turbulence intensity in boundary layer and hence fluid mixing which enhance the heat transfer performance. Many researchers studied experimentally the effect of vibration of equipment on the heat transfer. Penney and Jefferson [7] investigated experimentally the effect of the direction of vertical or horizontal oscillation (vibrated at low frequencies and large amplitudes) on the heat transfer coefficient of horizontal platinum wire in water and ethylene glycol. They found that heat transfer coefficient for vertical oscillation was higher than that for horizontal oscillation. The effect of vibration on natural convection heat transfer for a horizontal cylinder was studied by Lemlich and Rao [8]. They noted that as the amplitude and frequency of vibration were increased, the convective heat transfer coefficient was increased by up to ten times. Also, Dawood et al. [9] studied the effect of vertical vibrations on the free convection heat transfer for a horizontal cylinder in air. They concluded that the ratio between vibrational heat transfer coefficient and conventional (non-vibrational) heat transfer coefficient was linearly increased with vibration frequency. The heat transfer coefficient could be triple if vibrations was applied. Faircloth and Schaetzle [10] investigated experimentally the effect of vibration on the forced convection heat transfer coefficient. A chromax 40 gauge wires were vibrated in a horizontal plane by a sinusoidal current and simultaneously exposed to a forced air current in the same plane. The frequency and amplitude of the wire varied within the range 20 to $40 \mathrm{~Hz}$ and 0.3 to 0.5 in, respectively. Their results revealed that the instantaneous convective coefficient was increased from 20 to 30 percent if Reynolds number is more than its critical value. Saxena and Laired [11] described the effect of transverse oscillation on local heat transfer coefficient for a cylinder supported in a vertical position in open water channel. They found that both vibration amplitude and frequency were nearly equally contributed for increasing the local heat transfer coefficient. The increase in local heat transfer coefficient was about 50 to 60 percent and was occurred at the higher frequencies and amplitudes. Hsieh and Marsters [12] performed an experiment on a vibrating array of five identical heated cylinders. The vibrating array showed an increase in heat transfer rate of up to $54 \%$ for a range of vibration intensities from zero to 0.61. Eshghy et al. [13] obtained free convection heat transfer coefficient for a vertical plate subjected to oscillation. They showed a decrease in heat-transfer rate at low amplitudes vibrations. They concluded that for higher amplitudes, the increase in heat transfer was due to the change in the flow pattern. Finally, they found that the local vibrational Reynolds number must be higher than the local Grashof number to increase the heat transfer rate. Prasad and Ramanathan [14] studied experimentally the effect of longitudinal oscillations on the free convective heat transfer coefficient for a hot vertical plate. In this experiment, the frequencies ranging was from 10 to $20 \mathrm{cps}$ at an amplitude of $0.25 \mathrm{in}$, while the plate temperatures were varying from 100 to $200 \mathrm{~F}$. They showed that the vibration caused a significant increase in steady rate of heat transfer especially at low Rayliegh number. They found also that the maximum increase in heat transfer rate was $33 \%$. The influence of vibration on heat transfer for different geometries was conducted [15-19]. Saleh [15] studied the effect of vibration on heat transfer for $\mathrm{V}$ shaped grooves and square-shaped grooves corrugated plate. He found that the vibration was a powerful enhancement tool, where vibration increased the heat transfer rate by more than 2.5-fold. Eid and Gomaa [16] investigated the effect of vibration on heat transfer rate for thin planar fins. They found that the augmentation in rates of heat transfer reached $85 \%$ or more via normal vibration. Sarhan [17] conducted the investigation of the influence of vibration on the free convection performance for longitudinally finned plate. He reported a good enhancement in the heat transfer rate when vibrations were applied. Klaczak [18] carried out investigations concerns with the effect of vibrations on a horizontal steam-water heat exchanger. The vibration was in the same direction of the steam-water flow. The frequency was from 20 to $120 \mathrm{~Hz}$ and the amplitude was from 0.2 to $0.5 \mathrm{~mm}$. He clarified that the vibrations with high acceleration improve heat transfer in general. To avoid any damage in the construction of the equipment, the used frequency should away from the resonance frequency. Chatter and Sandeep [19] investigated the effect of vibration on a horizontal rectangular heat exchanger with five triangular baffles inclined at fixed 
angle of $20^{\circ}$ along the channel. The experiment was done on three different vibration intensities. Their results found that the overall heat transfer coefficient, $U$, showed the maximum increase of $70 \%$. The maximum effectiveness of $60.37 \%$ was found on vibration level of 6.5 . In the present study, a novel study about the effect of surface vibrations on the heat transfer coefficient of a GPHE is examined.

The present work is directed to study the effects of a low amplitude mechanical vibration under different working operating conditions on the performance characteristics of single-phase water flow inside a GPHE.

\section{Experimental work}

An Alfa Laval Model (S O5VW) GPHE with commercial chevron plates as shown in Fig. 1 is used. The plate is made of stainless steel with chevron angle of $30^{\circ}$. It has six plates, providing two hot channels and three cold channels in counter flow arrangement. Six independent immersion heaters, $3 \mathrm{~kW}$, are used to heat the water inside a 100 liters insulated tank. On/off switch and a digital thermostat are used to make a control on the hot temperature to be within $\pm 1^{\circ} \mathrm{C}$ deviation. For cold side, the municipal water is used. The amount water flow rate (hot or cold) is adjusted by two manually controlled valves. A $370 \mathrm{~W}$ with $2850 \mathrm{rpm}$ pump was utilized to circulate the hot water. Rotameters, model LZM-25G, with an accuracy of \pm 0.04 were used to measure the hot and cold-water volume flow rates. The hot water tank and piping, are well insulated by polyurethane foam and aluminum foil. A schematic diagram of the full test rig is shown in Fig.2.

Vibrations are generated by means of a grinding motor $(350 \mathrm{~W})$. The grinding wheel spindle is mounted on a sub-assembly, which is attached to the rigid platform by means of flexures which inhibit movement of the subassembly in all other directions. The grinding machine rigid platform is attached to the GPHE's platform. Variable speed AC inverter is used to regulate the motor rotational speed and hence vibration intensity. Temperature measurements are obtained by using J-type calibrated thermocouples $( \pm 0.1 \mathrm{~K})$ and 8 channels USB Data Acquisition Module. The thermocouples are located at GPHE inlets and outlets. Different vibrations frequency and amplitude are used to find their effect on heat transfer performance. Two-channel one Prod MVP$2 \mathrm{C}$ accelerometer is used to detect vibration dynamic response and vibration excitation displacement at three positions on the tested GPHE as shown in Fig. 3. Flexible connections were used for connecting the GPHE that subjected to vibration (oscillation) with the measuring sensors and the hot and cold-water loops in order to reduce transmission of vibration to the measuring devices and sensors. To start the system, the two circulating pumps are switched on. The used amount of water heaters is determined according to the required or designed temperature of hot water. The hot water inlet temperature, set using a thermostat, is approximately constant at $65^{\circ} \mathrm{C}$ during all experiments.

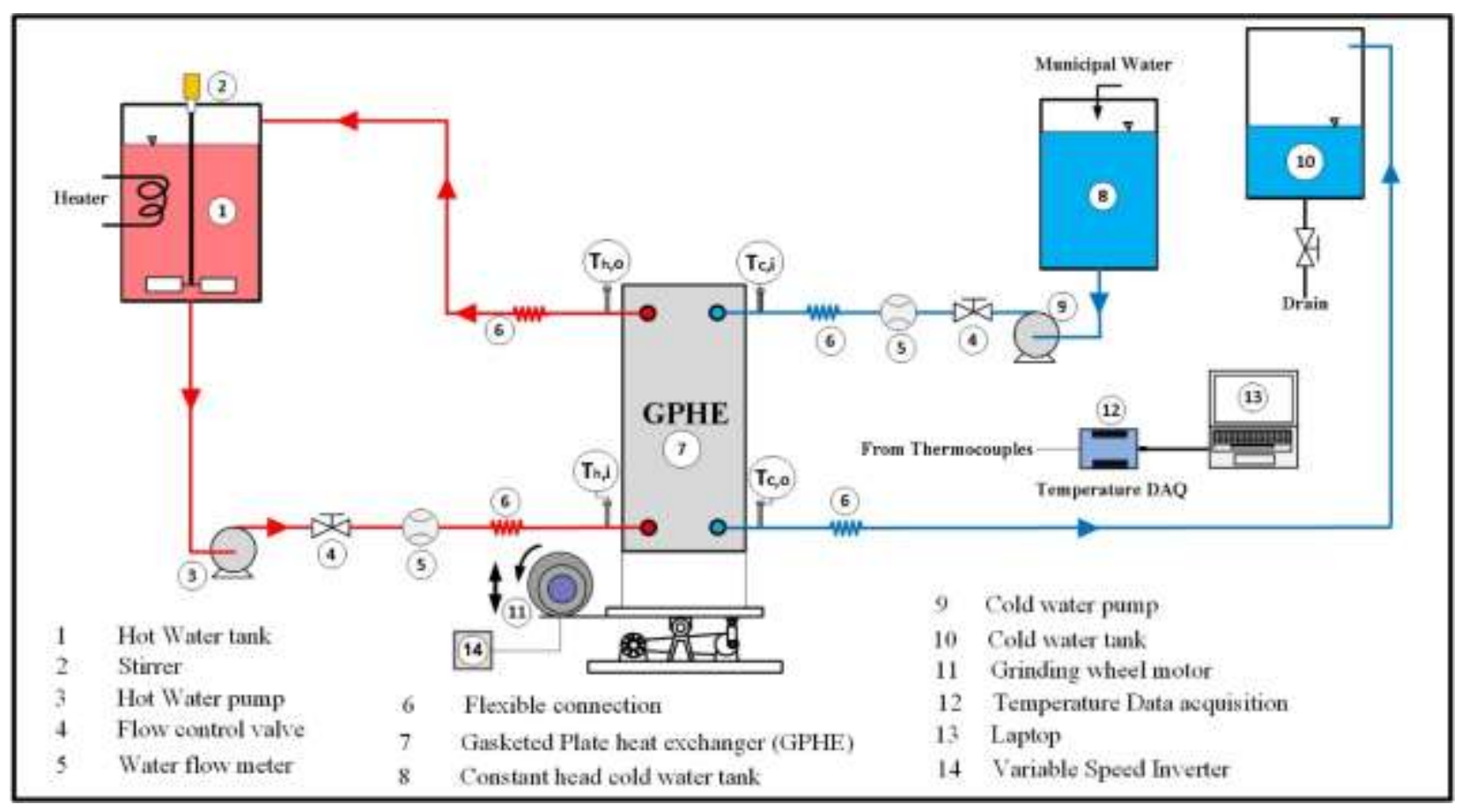

Fig. 2 Schematic diagram of the test rig with instrumentation. 


\subsection{Experimental uncertainty}

Let $w_{\mathrm{R}}$ be the uncertainty in the results and $\boldsymbol{w}_{\mathbf{1}}, \boldsymbol{w}_{\mathbf{2}}, \boldsymbol{w}_{\mathbf{3}}, \ldots$, $\boldsymbol{w}_{\mathbf{n}}$ be the uncertainties in the independent variables. If the uncertainties in the independent variables are all given with the same odds, then the uncertainty in the results having these odds is given by the following equation [20]:

$w_{R}=\left[\left(\frac{\partial R}{\partial X_{1}} w_{1}\right)^{2}+\left(\frac{\partial R}{\partial X_{2}} w_{2}\right)^{2}+\ldots\left(\frac{\partial R}{\partial X_{n}} w_{n}\right)^{2}\right]^{0.5}$ (1)

The experimental error analysis for all used working parameters is calculated by using Holman's method [20]. It is found that uncertainty analysis for Reynolds number, overall heat transfer coefficient, heat exchanger effectiveness and vibrational Nusselt number are \pm 3.22 , $\pm 3.85, \pm 4.89$ and \pm 3.99 respectively, which are within the agreeable range.

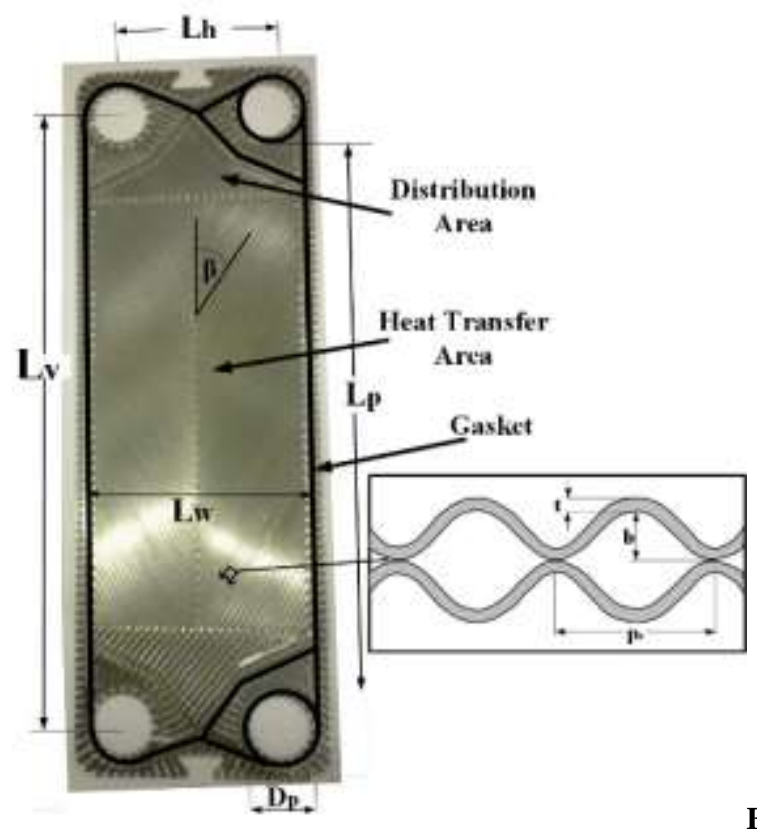

1. Basic geometric characteristics of chevron plate.

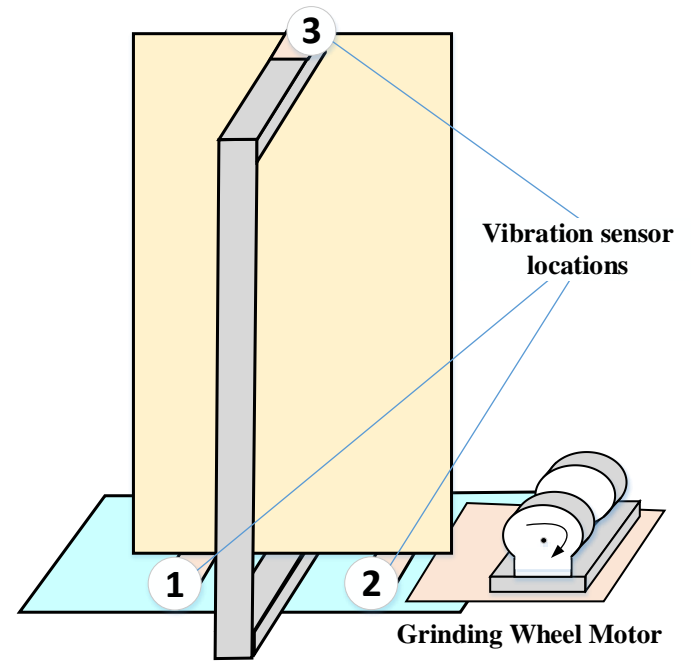

Fig. 3 Vibration Sensors locations

\section{Governing equations and calculation procedure.}

The heat exchanger capacity for hot and cold side may be calculated as follows:

$$
\begin{aligned}
& \dot{Q}_{h}=\dot{m}_{h} c_{p_{h}}\left(t_{h i}-t_{h o}\right) \\
& \dot{Q}_{c}=\dot{m}_{c} c_{p_{c}}\left(t_{c o}-t_{c i}\right)
\end{aligned}
$$

Ideally, the rate of heat lost from hot fluid, $\dot{\boldsymbol{Q}}_{\boldsymbol{h}}$, should be equal to the rate of heat gained to cold fluid, $\dot{\boldsymbol{Q}}_{\boldsymbol{c}}$ but actually they do not. This is due to heat losses to the surroundings or the measurement uncertainty. In the present experimental work, about only $5.4 \%$ maximum deviation is observed from calculations. The average heat transfer rates for the hot and cold is used:

$$
\dot{Q}_{a v}=\frac{\dot{Q}_{h}+\dot{Q}_{c}}{2}=U A \Delta T_{L M T D}
$$

The log mean temperature difference, $\Delta T_{L M T D}$ for counter flow arrangement and the effective area, $\boldsymbol{A}_{\mathbf{1}}$, can be calculated as [21]:

$$
\begin{aligned}
& \Delta T_{L M T D}=\frac{\left(t_{h i}-t_{c o}\right)-\left(t_{h o}-t_{c i}\right)}{\operatorname{Ln}\left(\left(t_{h i}-t_{c o}\right) /\left(t_{h o}-t_{c i}\right)\right)} \\
& A_{1}=L_{p} . L_{w} . \Phi . N_{e f f}
\end{aligned}
$$

From the previous equations, the overall heat transfer coefficient is obtained. The channel flow Reynolds number for GPHE is defined as:

$$
\boldsymbol{R e}=\left(\frac{\boldsymbol{G} \cdot \boldsymbol{D}_{e}}{\boldsymbol{\mu}}\right)
$$

Where $D_{e}$ is the equivalent diameter $\left(D_{e}=2 * b\right)$, and $G$ is the channel mass velocity may obtain as follows [21]:

$$
G=\left(\frac{\dot{m}}{N_{c . p} \cdot b \cdot w}\right)
$$

The number of channel per pass, $N_{c . p}$ is calculated as follow [22]

$$
N_{c . p}=\left(\frac{N t-1}{2 \cdot N_{p}}\right)
$$

The experimental Nusselt number as a function of the Reynolds number, the Prandtl, number and the ratio of the dynamic viscosities at bulk to wall temperature could be calculated as follow: [22].

$$
N u=C_{1} \cdot \operatorname{Re}^{P} \cdot \operatorname{Pr}^{\frac{1}{3}}\left(\frac{\mu}{\mu_{s}}\right)^{0.14}
$$

For the cold fluid, the convective heat transfer coefficient may be calculated as follow [23]:

$$
h_{c}=C_{1} \cdot \operatorname{Re}_{c}^{P} \cdot \operatorname{Pr}^{1 / 3}\left(\frac{\mu}{\mu_{s}}\right)_{C}^{0.14} \cdot \frac{K_{c}}{D e}
$$


Where the coefficient $\boldsymbol{C}_{\mathbf{1}}$ and $\boldsymbol{P}$ are constant and the value coefficient, $\boldsymbol{P}$, is between 0 and 1 [23]. The modified Wilson plot technique [24] was used in order to find the coefficient $\boldsymbol{C}_{\mathbf{1}}, \boldsymbol{P}$, and the hot convective heat transfer coefficient by using MATLAB computer code. This done after calculating the overall heat coefficient, for cleaning surfaces as follow:

$$
\frac{1}{U}=\frac{1}{h_{h}}+\frac{t}{k_{w}}+\frac{1}{h_{c}}
$$

The effectiveness $(\varepsilon)$ and effectiveness enhancement ratio, $\varepsilon / \varepsilon_{0}$, of the GPHE can be calculated as follow:

$$
\varepsilon=\frac{C_{h}\left(t_{h i}-t_{h o}\right)}{C_{\min }\left(t_{h i}-t_{c i}\right)}=\frac{C_{c}\left(t_{c o}-t_{c i}\right)}{C_{\min }\left(t_{h i}-t_{c i}\right)}
$$

$$
\frac{\varepsilon}{\varepsilon_{0}}=\frac{G P H E \text { effectivness with vibration }}{\text { GPHE ef fectivness with out vibration }}
$$

When vibration is applied the Reynolds number oscillation $\left(\operatorname{Re}_{\text {osc }}\right)$, may be calculated as follow:

$$
\boldsymbol{R} e_{o s c}=\left(A . \omega . D_{e}\right) /(\mu / \rho)
$$

The product $(A * \omega)$ is called vibration intensity. The geometrical parameter known as the dimensionless oscillation amplitude $\left(\mathrm{A} / \mathrm{D}_{\mathrm{e}}\right)$, is the ratio of the vibration amplitude to the GPHE channel equivalent diameter.

\section{Results and discussion}

In the present study, the effect of surface vibrations on the heat transfer coefficient of a GPHE is examined.

\subsection{GPHE Nusselt number without vibration}

Fig. 4 and Table 1 illustrate the relation between Nusselt number and Reynolds number for GPHE for present work and previous works [25 to 28]. It could be seen from this Fig. that, Nusselt number value increases as the flow Reynolds number increases. The Nusselt number behavior for the tested GPHE is similar that for all previous work. Although all the compared GPHE have similar corrugation inclination angle $\left(\beta=30^{\circ}\right)$, height and wavelength of the corrugations are different which lead to a slight difference between the result's values. Another reason for these differences is that the numbers of hot and cold channel are as well different [28].

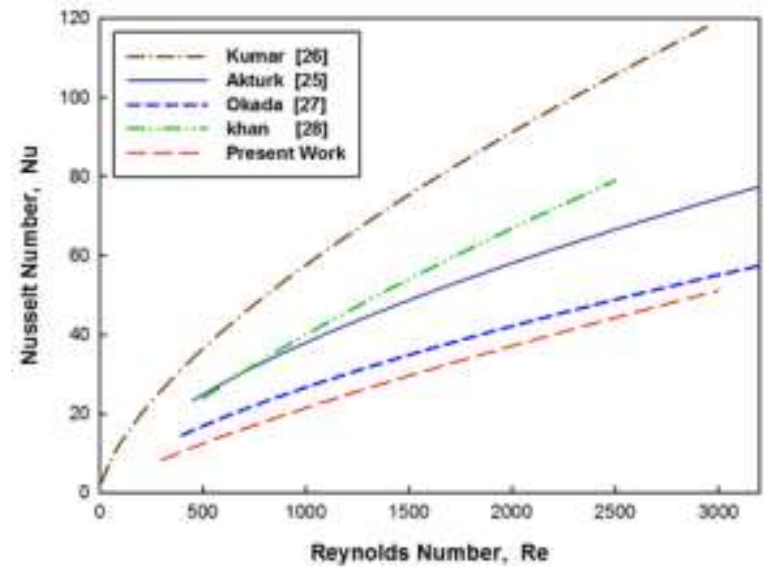

Fig. 4 Comparison between present work Nusselt number with previous work Nusselt number

Table (1) The present correlation for Nusselt number and the similar correlations from the literature.

\begin{tabular}{|c|c|c|}
\hline Ref. & Correlation & Re range \\
\hline $\begin{array}{c}\text { Present } \\
\text { correlation }\end{array}$ & $N u=0.042 \cdot \operatorname{Re}^{0.791} \cdot \operatorname{Pr}^{\frac{1}{3}}\left(\frac{\mu}{\mu_{w}}\right)^{0.14}$ & $300-3000$ \\
\hline $\begin{array}{c}\text { Okada et al. } \\
{[27]}\end{array}$ & $N u=0.1528 \cdot \operatorname{Re}^{0.66} \cdot \operatorname{Pr}^{0.4}$ & $400-15000$ \\
\hline $\begin{array}{c}\text { Akturk et al. } \\
{[25]}\end{array}$ & $N u=0.32673 \cdot \operatorname{Re}^{0.6125} \cdot \operatorname{Pr}^{\frac{1}{3}}\left(\frac{\mu}{\mu_{w}}\right)^{0.14}$ & $450-5250$ \\
\hline $\begin{array}{c}\text { Khan et al. } \\
{[28]}\end{array}$ & $N u=0.1368 \cdot \operatorname{Re}^{0.7424} \cdot \operatorname{Pr}^{0.35}\left(\frac{\mu}{\mu_{w}}\right)^{0.14}$ & $500-2500$ \\
\hline $\begin{array}{c}\text { Kumar H. } \\
{[26]}\end{array}$ & $N u=0.348 \cdot \operatorname{Re}^{0.663} \cdot \operatorname{Pr}^{\frac{1}{3}}\left(\frac{\mu}{\mu_{w}}\right)^{0.17}$ & $>10$ \\
\hline
\end{tabular}

\subsection{GPHE Nusselt number correlations with vibration}

An attempt is made to correlate the results was obtained from the MATLAB software by using the Wilson plot technique for determining the vibrational Nusselt number correlation constant $\boldsymbol{C}_{\mathbf{1}}$ and index $\boldsymbol{P}$. The results are as follows:

$$
\begin{gathered}
C_{1}=0.042-2.1 * 10^{-4} \cdot \operatorname{Re}_{\mathrm{osc}} 0.531 \cdot\left(\frac{A}{D_{\mathrm{e}}}\right)^{-0.605} \\
\mathrm{P}=0.791+1.883 * 10^{-4} \cdot \operatorname{Re}_{\mathrm{osc}} 0.753 \\
\cdot\left(\frac{A}{D_{\mathrm{e}}}\right)^{-0.846}(17)
\end{gathered}
$$

Fig. 5 illustrates the relation between the coefficient $\boldsymbol{C}_{\mathbf{1}}$ and index $\boldsymbol{P}$ as a function of Reynolds number oscillation $\left(\operatorname{Re}_{\text {osc }}\right)$ at constant $\left(A / D_{\mathrm{e}}\right)=0.03$. It could be noted that as Reynolds number oscillation $\left(\mathrm{Re}_{\mathrm{osc}}\right)$ increases, the value of index $\boldsymbol{P}$ increases and the value of coefficient $\boldsymbol{C}_{\mathbf{1}}$ decreases. Fig. 6 illustrates the relation between the coefficient $\boldsymbol{C}_{\mathbf{1}}$ and index $\boldsymbol{P}$ as a function of dimensionless oscillation amplitude $\left(\mathrm{A} / \mathrm{D}_{\mathrm{e}}\right)$ at constant Reynolds number oscillation $\left(\operatorname{Re}_{\mathrm{osc}}\right)=100$. It could be noted that as dimensionless oscillation amplitude $\left(\mathrm{A} / \mathrm{D}_{\mathrm{e}}\right)$ increases, the value of coefficient $\boldsymbol{C}_{\mathbf{1}}$ increases and the value of index $\boldsymbol{P}$ 
decreases. From both Figs. 5 and 6, it could be deduced that with the increase of both vibration amplitude and frequency the heat transfer performance of the vibrated PHE was enhanced but with increasing the vibration frequency and decreasing the vibration amplitude the heat transfer enhancement is decreased. The best enhancement occurs when the vibration amplitude increased where the vibration frequency decreased. Fig. 7 illustrates the relation between vibration amplitude, vibration frequency, and grinding motor speed. It could be noted from this figure that vibration amplitude is directly proportional to vibration frequency and grinding motor speed until resonance condition is occurred, and then turns to inversely proportional. The resonance condition occurs at the maximum vibration amplitude (at $1690 \mathrm{rpm}$ and $\mathrm{Re}_{\mathrm{osc}}$ of 209.34) and vibration natural frequency $\omega_{\mathrm{n}}=28.3 \mathrm{cps}$.

Fig. 8 shows the relation between heat transfer coefficient enhancement ratio and oscillation $\left(\mathrm{Re}_{\mathrm{osc}}\right)$ with 800 to 1800 rpm. It is observed generally that the heat transfer coefficient, $\mathrm{h}$ increases as oscillation Reynolds number increases. The heat transfer coefficient for oscillating GPHE is higher than that for stationary one. Moreover, heat transfer enhancement ratio increases as Reynolds number oscillation increases. The maximum heat transfer enhancement ratio occurs at $\operatorname{Re}_{\text {osc }}=211.34$, which has vibration amplitude $\left(\mathrm{A} / \mathrm{D}_{\mathrm{e}}\right)$ of $52.66 * 10^{-3}$. The value of this vibration amplitude is just after its value for resonance condition, as shown in Fig.7.

It could be noted from Fig. 8 also that at $\operatorname{Re}_{\text {osc }}=211.34$, the heat transfer coefficient for vibrating GPHE could be higher than that for stationary GPHE by about $43 \%$. This is because the vibrated GPHE rise flow turbulence in the vicinity of the boundary layers and hence decrease its thickness. This causes a good enhancement in heat transfer, as pointed out by Benhamou [29].

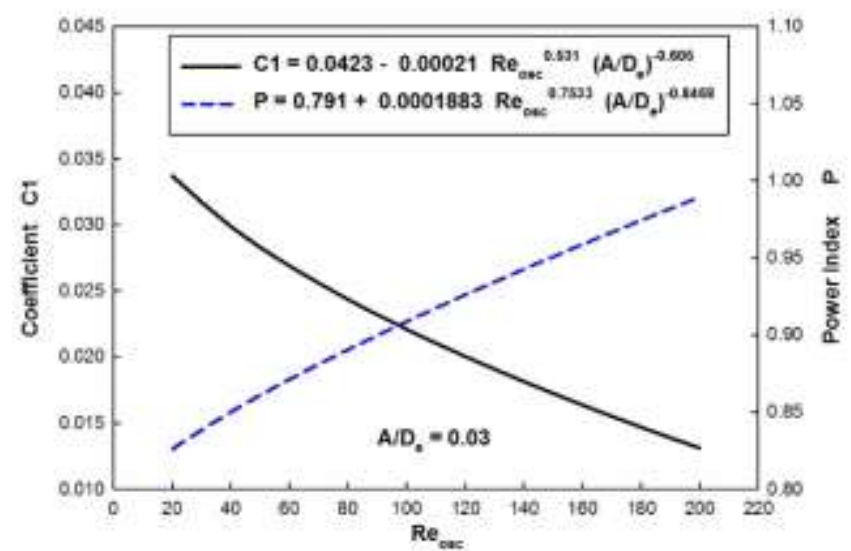

Fig. 5 Change of the coefficient $C_{1}$ and the index $P$ of the new Nusselt number correlation with the $\mathbf{R e}_{\text {osc }}$ at constant value of $A / D_{e}=0.03$.

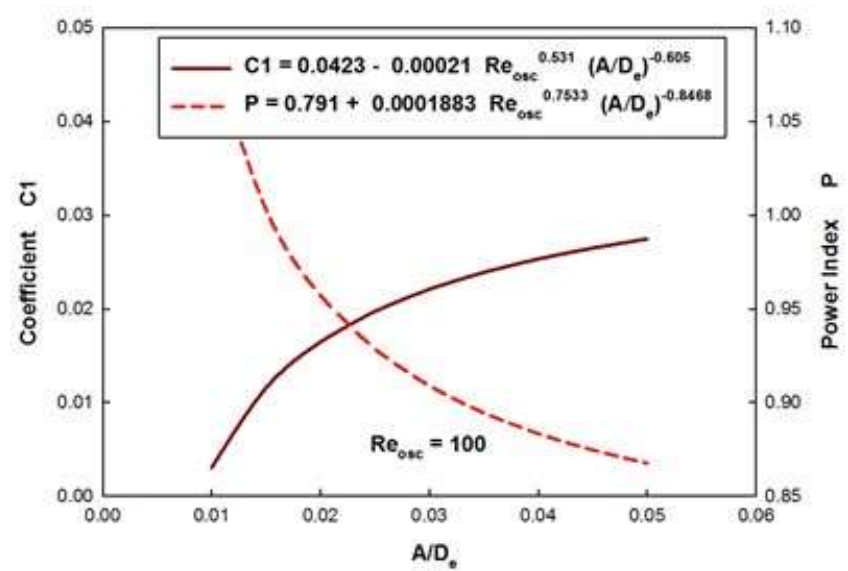

Fig. 6 Change of the coefficient $C_{1}$ and the index $P$ of the new Nusselt number correlation with the $A / D_{e}$ at constant value of $\boldsymbol{R e}_{\text {osc }}=\mathbf{1 0 0}$.

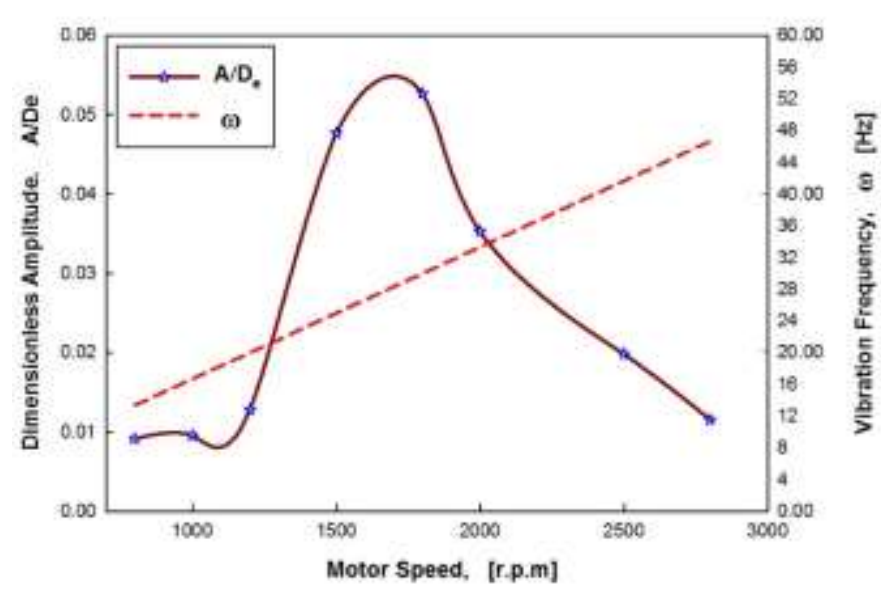

Fig. 7 Change of vibration amplitude and frequency with the grinding motor speed.

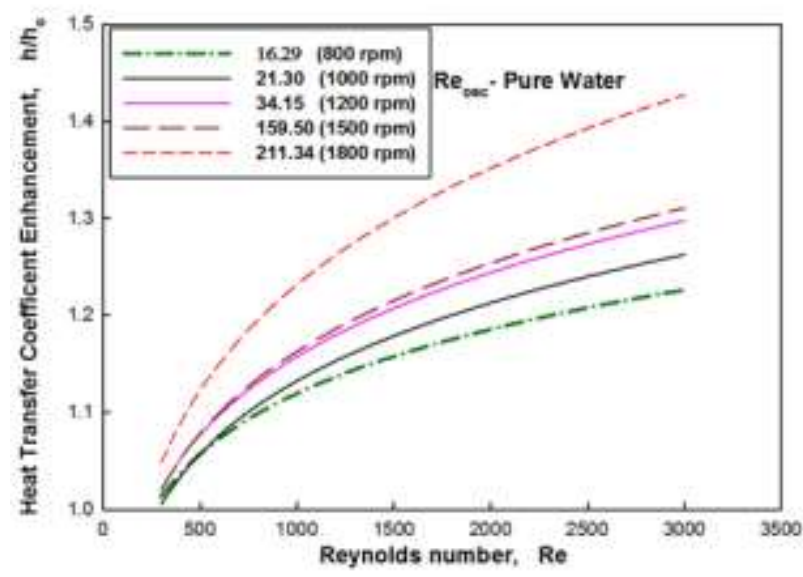

Fig. 8 Effect of flow Reynolds number on the heat transfer coefficient enhancement ratio at different GPHE oscillation Reynolds number, Re osc. From 800 to $1800 \mathrm{rpm}$.

Fig. 9 shows the relation between heat transfer coefficient enhancement ratio and Reynolds number for Reynolds number oscillation $\left(\mathrm{Re}_{\mathrm{osc}}\right.$ ) with 2000 to $2800 \mathrm{rpm}$. In this period, as grinding motor speed increases, Reynolds 
number oscillation decreases, and hence heat transfer enhancement ratio significantly decreases. This is because vibration amplitude is decreased as shown in Fig. 7.

\subsection{GPHE effectiveness enhancement with vibration.}

Fig. 10 illustrates the relation between flow Reynolds number and GPHE effectiveness enhancement ratio $\left(\varepsilon / \varepsilon_{\circ}\right)$ at different values of oscillation Reynolds number.

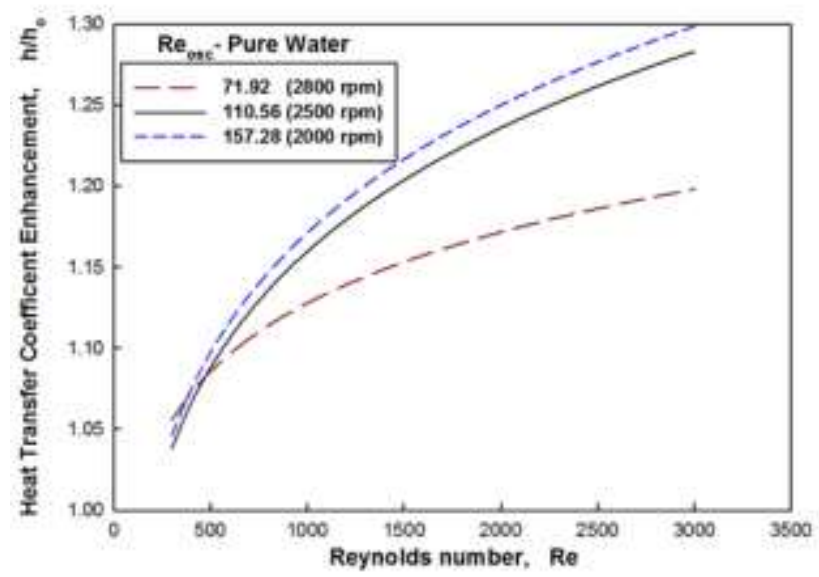

Fig. 9 Effect of flow Reynolds number on the heat transfer coefficient enhancement ratio at different

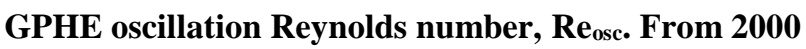
to $2800 \mathrm{rpm}$.

It is clear that the effectiveness enhancement ratio increases as Reynolds number increases. For a certain value of Reynolds number, the effectiveness enhancement ratio increases significantly as the oscillation Reynolds number increases, and the maximum effectiveness enhancement ratio is equal to $18 \%$, which accomplishes at the higher $\operatorname{Re}_{\mathrm{osc}}=211.34$. This is happened after the natural frequency (Resonance) occurs. This is because as the $\mathrm{Re}_{\text {osc }}$ reaches its maximum value, the reinforced turbulence mixing of flow inside the vibrating PHE occurs. Also, this is due to the secondary flow that occurs in the transversal direction that result from the vertical vibration force. This causes convective currents across the PHE section, and induces a strong momentum transfer, that enhance the performance of the heat transfer.

Fig. 11 shows the change of the overall heat transfer coefficient enhancement ratio with flow Reynolds number inside the channels of GPHE at different values of oscillation Reynolds number, for a specific value of heat capacity rate ratio equal 1.0. When Reynolds number increases (mass flow rate in channel increases), the overall heat transfer coefficient enhancement ratio $\left(\mathrm{U} / \mathrm{U}_{\mathrm{o}}\right)$ increases.

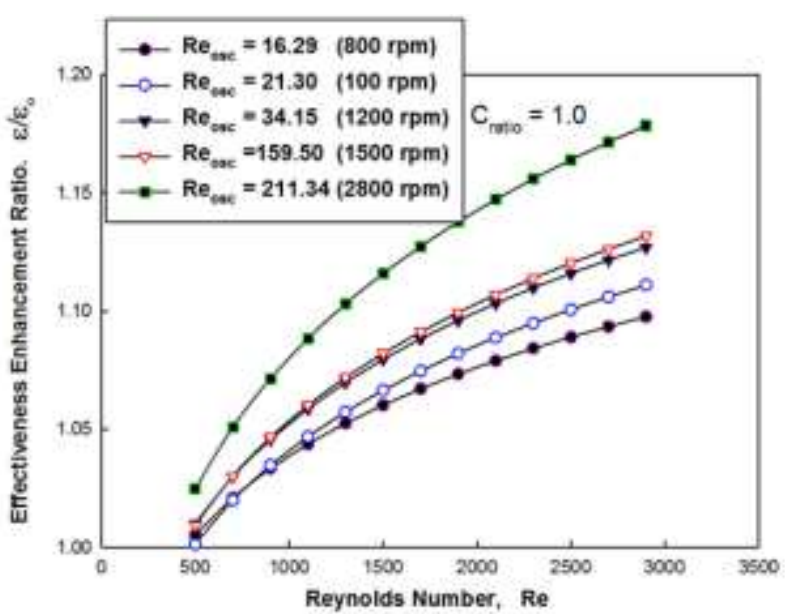

Fig. 10 Variation of effectiveness enhancement ratio with Reynolds number, for different values of oscillation Reynolds number and $\mathrm{C}_{\mathrm{R}}=\mathbf{1 . 0}$.

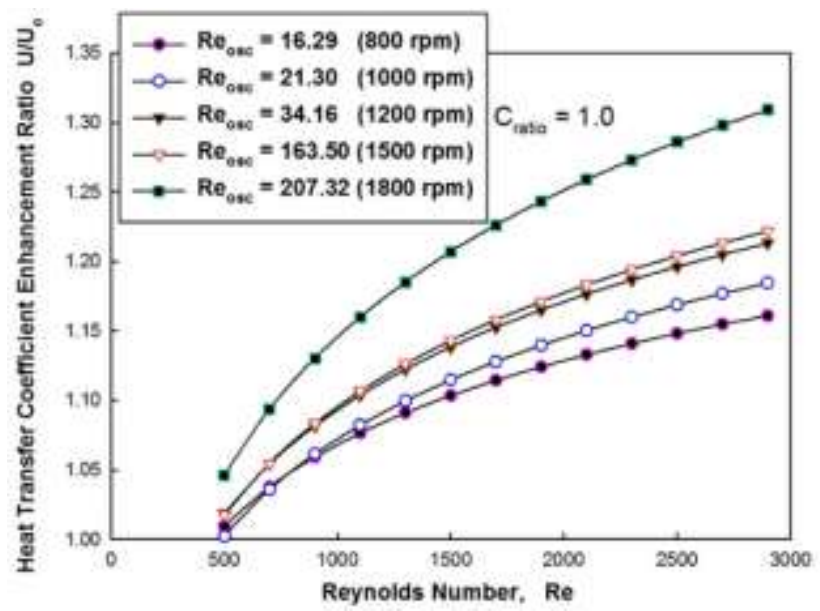

Fig. 11 Variation of overall heat transfer coefficient enhancement ratio with Reynolds number, for different values of oscillation Reynolds number and at $\mathrm{C}_{\mathrm{R}}=\mathbf{1 . 0}$.

This is because as Reynolds number inside channel of GPHE increases, both hot and cold heat transfer coefficients (hh\&hc) increase and hence overall heat transfer coefficient enhancement ratio increases also. At a certain value of Reynolds number, when the oscillation Reynolds number increases, especially when both the vibrational amplitude and frequency increases, the overall heat transfer enhancement ratio increases. The maximum enhancement in (U/Uo) is equal to $31 \%$, and this maximum enhancement ratio in $U$ is achieved when the vibrating PHE is after the natural frequency (Resonance) occurs at an oscillation Reynolds number equal to 211.34. This is because the flow reinforced turbulence mixing as the PHE vibration intensity increase. In addition, because the generated convective currents across the GPHE section, which arise from the secondary flow that occurs in the transversal direction result from the vertical vibration force. 


\section{Conclusions}

Experiments are performed with a commercial GPHE. The final conclusions from the present study can be summarized as follow:

1- As a general trend, both heat transfer coefficient and PHE effectiveness are significantly increase as vibration intensity (represented by oscillation Reynolds number) increases.

2- The maximum values of percentage enhancement for heat transfer coefficient, overall heat transfer coefficient and GPHE effectiveness are $43 \%, 31 \%$ and $18 \%$, respectively with comparison with the nonvibrational case. These values have taken place after the resonance conditions at oscillation Reynolds number $=211.34$ and $\mathrm{A} / \mathrm{De}=52.66 * 10^{-3}$.

3- Below grinding motor speed of $1800 \mathrm{rpm}$ (i.e. at $\mathrm{Re}_{\mathrm{osc}}=211.34$ ), both vibration frequency and vibration amplitude are directly proportional to GPHE heat transfer enhancement ratio.

However, for higher grinding motor speed, vibration frequency is increased and both vibration amplitude and GPHE heat transfer enhancement ratio are decreased.

4- New vibrational Nusselt number correlation as a function of Reynolds number, oscillation Reynolds number and dimensionless vibration amplitudeis is obtained with a relative error of $3.99 \%$.

5- For stationary mode, the proposed correlations showed a good agreement with these found in the previous work.

\section{Nomenclature}

$A_{1} \quad$ Effective heat transfer area, $\left[\mathrm{m}^{2}\right]$

$\mathrm{A}$, or Vibration amplitude, [mm].

b Plate corrugation depth or mean channel spacing, [m].

$\mathrm{C}_{\mathrm{p}} \quad$ Specific heat at constant pressure, $[\mathrm{J} / \mathrm{kg} . \mathrm{K}]$.

C Mass capacitance rate, $[\mathrm{W} / \mathrm{K}]$.

$\mathrm{C}_{\mathrm{R}} \quad$ Heat capacity rate ratio, [dimensionless].

D Diameter, [m].

$\mathrm{D}_{\mathrm{e}} \quad$ Equivalent diameter of flow passages, [m].

G Channel mass velocity, $\left[\mathrm{kg} / \mathrm{m}^{2} . \mathrm{s}\right]$

h Convection heat transfer coefficient, $\left[\mathrm{W} / \mathrm{m}^{2}\right.$. $\mathrm{K}]$.

$\mathrm{k} \quad$ Effective thermal conductivity, [W/m. K].

$\mathrm{L}_{\mathrm{p}} \quad$ Effective plate length, (m).
$\mathrm{L}_{\mathrm{w}} \quad$ Effective plate width, [m].

$\dot{\mathrm{m}} \quad$ Mass flow rate, $[\mathrm{kg} / \mathrm{s}]$.

$N_{c p} \quad$ Number of channels per pass as defined in equ. (9)

$N_{\text {eff }} \quad$ Number of all thermally effective plates

$N_{p} \quad$ Number of flow passes on the given fluid side.

$N_{t} \quad$ Total number of GPHE plates.

$\mathrm{Nu} \quad$ Nusselt number, [dimensionless].

$N u_{v i b} \quad$ Vibrational Nusselt number, [dimensionless].

$\mathrm{P}_{\mathrm{r}} \quad$ Prandtl number, [dimensionless].

Q. Heat transfer rate, $[\mathrm{W}]$.

Re Reynolds number, [dimensionless].

$\mathrm{Re}_{\mathrm{osc}} \quad$ Oscillation Reynolds number, [dimensionless]

Temperature degree, $\left[\mathrm{K}\right.$ or $\left.{ }^{\circ} \mathrm{C}\right]$ or Plate thickness, [m].

$\Delta \mathrm{T} \quad$ Temperature difference, $\left[\mathrm{K}\right.$ or $\left.{ }^{\circ} \mathrm{C}\right]$.

$\mathrm{U} \quad$ Overall heat transfer coefficient, $\left[\mathrm{W} / \mathrm{m}^{2} . \mathrm{K}\right]$

$\mathrm{U} / \mathrm{U}_{\mathrm{o}} \quad$ Overall heat transfer coefficient enhancement

\section{Subscripts}
av Average.
h hot side
C cold side
i, o inlet /outlet
e Equivalent.
r, R Ratio, or results
w or s Wall or surface.
C.P Channel per pass.
LMTD Logarithmic mean temperature difference osc cillation

\section{Greek symbols}
$\omega$, or $\mathrm{f}$ Vibration frequency, [cps].
$\phi \quad$ Surface enlargement factor, [dimensionless].
$\boldsymbol{\varepsilon} \quad$ Effectiveness, [dimensionless].
$\mu \quad$ Dynamic viscosity, $[\mathrm{Pa} . \mathrm{s}]$ or $\left[\mathrm{N} * \mathrm{~S} / \mathrm{m}^{2}\right]$.
$\boldsymbol{\beta} \quad$ Plate corrugation angle, [degree].
$\varepsilon / \varepsilon_{\circ} \quad$ Effectiveness enhancement ratio, [dimensionless]. 


\section{References}

[1] Shankara Murthy.H.M, and R. N. Hegde, " A critical review of combined augmentation techniques used for heat transfer enhancement in heat exchangers " National Conference on Advances in Mechanical Engineering Science (NCAMES-2016).

[2] IEA, "International Energy Agency report, 2009" [On line] Available: http://www.iea.org/topics/heat/

[3] Kays, W.M. and A.L. London, "Compact heat exchangers" Krieger Publishing Company, $3^{\text {rd }}$ ed. 1984.

[4] Palm, B., "Heat transfer in microchannels" Microscale Thermophysical Engineering, 2001. 5(3): p. 155-175.

[5] Steinhagen, R., H. Müller-Steinhagen, and K. Maani, "Problems and costs due to heat exchanger fouling in New Zealand industries" Heat transfer engineering, 1993. 14(1): p. 19-30.

[6] Bergles, A.E., "Techniques to augment heat transfer", "Handbook of Heat Transfer", McGraw-Hill: New York, $3^{\text {rd }}$ ed., 1998.

[7] Penney, W.R. and T.B. Jefferson, "Heat transfer from an oscillating horizontal wire to water and ethylene glycol " ASME journal of Heat Transfer, 1966. 88: p. 359-366.

[8] Lemlich, R. and M.A. Rao, "The effect of transverse vibration on free convection from a horizontal cylinder" International Journal of Heat and Mass Transfer, 1965. 8(1): p. 27-33.

[9] Dawood, A., B. Manocha, and S. Ali, "The effect of vertical vibrations on natural convection heat transfer from a horizontal cylinder" International Journal of Heat and Mass Transfer, 1981. 24(3): p. 491-496.

[10] Faircloth, J. and W.J. Schaetzle, "Effect of vibration on heat transfer for flow normal to a cylinder" Journal of Heat Transfer, 1969. 91(1): p. 140-144.

[11] Saxena U.C. and A.D.K. Laird, "Heat transfer from a cylinder oscillating in a cross-flow" Journal of heat transfer 1978. 100: p. 684-689.

[12] Hsieh, R. and G. Marsters, "Heat transfer from a vibrating vertical array of horizontal cylinders" The Canadian Journal of Chemical Engineering, 1973. 51(3): p. 302-306.

[13] Eshghy, S., V. Arpaci, and J. Clark, "Closure to "Discussion of The Effect of Longitudinal Oscillations on Free Convection from Vertical Surfaces" " ASME J. Journal of Applied Mechanics, 1965. 32: p. 183-191.

[14] Prasad, K.K. and V. Ramanathan, "Heat transfer by free convection from a longitudinally vibrating vertical plate" International Journal of Heat and Mass Transfer, 1972. 15(6): p. 1213-1223.

[15] Saleh, M. A., "Enhancement of convective heat transfer on a flat plate by artificial roughness and vibration", in Proceeding of the 2006 WSEAS/IASME International Conference on Heat and Mass Transfer 2006. p. 69-77.

[16] Eid, E. and M. Gomaa, "Influence of vibration in enhancement of heat transfer rates from thin plannar fins" Heat and mass transfer, 2009. 45(6): p. 713-726.
[17] Sarhan, A.R., "Vertical Forced Vibration Effect on Natural Convective Performance of Longitudinal Fin Heat Sinks" Tikrit Journal of Engineering Sciences, 2013. 20(2): p. 60-69.

[18] Klaczak, A., "Report from experiments on heat transfer by forced vibrations of exchangers" Heat and Mass transfer, 1997. 32(6): p. 477-480.

[19] Chatter Pal, S. and K. S. Sandeep, "Effect of Vibration on Heat Transfer Enhancement in a Rectangular Channel Heat Exchanger", in National Conference on Advances in Engineering Technology \& Managements, AETM 15. p. 51-57.

[20] Holman J. P., "Experimental Methods for Engineers", fifth ed., McGrow-Hill, New York, 1989.

[21] Kakaç, S., H. Liu, and A. Pramuanjaroenkij, "Heat Exchangers: Selection, Rating, and Thermal Design" CRC Press, 2012, (Chapter 11).

[22] Muley, A., "Heat transfer and pressure drop in plate heat exchangers" Ph. D. Theses, 1998.

[23] Muley, A, R. M. Manglik, enhanced heat transfer characteristics of a chevron plate heat exchanger for viscous fluid thermal processing applications, proceeding of the ASME, heat transfer division Vol. 3 (1998), PP:459-466.

[24] Fernandez-Seara, J., F. J. Uhia, J. Sieres, and A. Campo, "A general review of the Wilson plot method and its modifications to determine convection coefficients in heat exchange devices" Applied Thermal Engineering, 2007. 27(17-18): p. 2745-2757.

[25] Akturk, F, N. Sezer-Uzol, S. Aradag and S. Kakac "Experimental Investigation and Performance Analysis of Gasketed-Plate Heat Exchangers" J. of Thermal Science and Technology, 2015. 35(1): p. 4352.

[26] Kumar, H. "The plate heat exchanger: construction and design" in Institute of Chemical Engineering Symposium Series. 1984

[27] Okada, K,, Ono, M., Tomimura, T, Okuma, T, Konno, H., and Ohtani, S., "Design and Heat Transfer Characteristics of a New Plate Heat Exchanger," Heat Transfer-Japanese Research, 1972.Vol. 1, No. 1, pp. 90-95.

[28] Khan, T.S. M.S. Khan, Ming-C. Chyu , Z.H. Ayub , "Experimental investigation of single phase convective heat transfer coefficient in a corrugated plate heat exchanger for multiple plate configurations", Applied Thermal Engineering, 2010. 30. P. 1058-1065.

[29] Benhamou, B., Galanis, N. and Laneville, A. "Transient effects of orthogonal pipe oscillations on laminar developing incompressible flow" International Journal for Numerical Methods in Fluids, 2000. 34(7): p. 561-584. 